\title{
CASOS DE VIOLÊNCIA VERBAL NO FUTEBOL E NAS REDES DE COMPUTADOR À LUZ DA TEORIA DOS ATOS DE LINGUAGEM
}

(Events of verbal violence in soccer and computer networks in light of language act theory)

\author{
Manoel Francisco Guaranha ${ }^{1}$ \\ (Universidade Santo Amaro-UNISA e Faculdade de Tecnologia de São Paulo- FATEC) \\ Álvaro Cardoso Gomes ${ }^{2}$ \\ (Universidade Santo Amaro-UNISA e Universidade de São Paulo - USP)
}

\begin{abstract}
RESUMO
Este artigo analisa enunciados sobre futebol e sobre a vida de uma celebridade, reproduzidos pela Internet ou produzidos nela, com a finalidade de compreender os mecanismos da injúria e do insulto, bem como a função das circunstâncias em seus modos de expressão. Para tanto, baseia-se na teoria dos atos de fala (Austin e Searle); na teoria da construção e da preservação das faces (Goffman); e nos conceitos de Face Threatening Acts (FTAs) e Face Flattering Acts (FFAs) (Brown e Levinson), estes apontados por Kerbrat-Orecchioni como recicladores dos conceitos de atos de fala que desenvolvem uma nova teoria da polidez e, consequentemente, da impolidez. As práticas de violência verbal por meio de atos de linguagem indiretos ganham força ilocucionária em ambientes virtuais ou reais em que o indivíduo sente-se protegido pelo grupo ou pela sensação de anonimato.
\end{abstract}

Palavras-chave: Atos de linguagem. Violência Verbal. Face Threatening Acts (FTAs). Face Flattering Acts (FFAs). Impolidez e Polidez linguísticas.

\begin{abstract}
This article analyzes statements about football and about a celebrity's life, reproduced on or produced on the Internet, in order to understand the mechanisms of injury and insult, as well as the function of circumstances in their modes of expression. To this end, it is based on the theory of speech acts (Austin and Searle); in the theory of construction and preservation of faces (Goffman); and in the concepts of Face Threatening Acts (FTAs) and Face Flattering Acts (FFAs) (Brown and Levinson), these pointed by Kerbrat-Orecchioni as recyclers of speech act concepts, that develop a new theory of politeness and, consequently, impoliteness. The practices of verbal violence through indirect language acts acquire illocutionary force in real or virtual environments where the person feels protected by the group or by the feeling of anonymity.
\end{abstract}

Keywords: Acts of language. Verbal Violence. Face Threatening Acts (FTAs). Face Flattering Acts (FFAs). Linguistic impolity and politeness.

\section{RESUMEN}

Este artículo analiza las declaraciones sobre el fútbol y sobre la vida de una celebridad, reproducidas o producidas en Internet, con el fin de comprender los mecanismos de denuestos e insultos, así como la función de las circunstancias en sus modos de expresión. Para este fin, se basa en la teoría de los actos de habla (Austin y Searle); en la teoría de la construcción y preservación de rostros (Goffman); y en los conceptos de Face Threatening Acts (FTAs) y Face Flattering Acts (FFAs) (Brown y Levinson), estos señalados por Kerbrat-Orecchioni como recicladores de conceptos de actos de habla que desarrollan una nueva teoría de la cortesía y, en consecuencia, la descortesía. Las prácticas de violencia verbal a través de actos indirectos

\footnotetext{
${ }^{1}$ Manoel Francisco Guaranha é Doutor em Letras, Literatura Portuguesa pela USP/SP. Professor concursado da Faculdade de Tecnologia de São Paulo (FATEC) e docente do Programa de Mestrado em Ciências Humanas da Universidade Santo Amaro (UNISA). E- mail: manoel.guaranha@ gmail.com

2 Álvaro Cardoso Gomes é Doutor em Letras, Literatura Portuguesa pela USP/SP; Livre-docente pela USP/SP; Pósdoutor em Portugal e nos Estados Unidos. Professor Titular da USP/SP e coordenador do Programa de Mestrado em Ciências Humanas da Universidade Santo Amaro (UNISA). E-mail: acgomes@ prof.unisa.br
} 
del lenguaje ganan fuerza ilocucionaria en entornos virtuales o reales donde el individuo se siente protegido por el grupo o por el anonimato.

Palabras clave: Actos de lenguaje. Violencia verbal. Actos de amenaza para la cara (TLC). Actos de adulación facial (FFA). Lenguaje impolito y cortés.

Recebido em: dezembro 2019

Aceito em: dezembro 2019

DOI: $\underline{10.26512 / \text { les.v20i2.28713 }}$

\section{INTRODUÇÃO}

Este artigo tem como finalidade analisar enunciados reproduzidos na Internet ou produzidos nela para compreender os modos de construção e o valor ilocucionário deles como atos de linguagem indiretos que constituem agressões à face alheia e práticas de violência verbal. Para tanto, serão apresentados aspectos da teoria de atos de fala ou atos de linguagem, as categorias em que esses atos podem ser divididos, as circunstâncias em que são expressos e que os tornam capazes de produzir os efeitos que produzem, circunstâncias estas que estão ligadas à intencionalidade que os reveste. Além disso, a essas considerações serão articulados conceitos da teoria das faces nas interações sociais e a noção de construção de atos agressores da face (ou Face Threatening Acts - FTAs) que são, às vezes, compensados por atos reparadores da face (ou Face Flattering Acts - FFAs).

O método utilizado para a análise consiste em identificar e descrever, em duas situações concretas de interação (uma real e outra virtual), ambas com repercussão na Internet, os modos como foram construídos estrategicamente os atos de linguagem indiretos, levando em conta que esses atos nem sempre formulados explicitamente e constituem instrumentos de agressão verbal que revelam ou estimulam a violência por meio do preconceito notadamente em duas frentes: a da injúria e a do insulto que manifestam, respectivamente, práticas de racismo e de exclusão social de minorias.

Sem entrar em questões jurídicas mais aprofundadas, partiremos do pressuposto de que a injúria é, do ponto de vista do Direito, ilícito penal praticado por quem ofende a honra e a dignidade de outrem, e que o insulto é prática difamatória. Ambos os atos de violência verbal estão previstos no Título I, "Dos crimes contra a pessoa", no capítulo V, que trata "Dos crimes contra a honra", do Código Penal Brasileiro. Essas práticas violam um bem jurídico imaterial do indivíduo, que é a honra, e têm ganhado espaço na atual sociedade da informação na medida em que "a rede mundial de computadores [...] permite enorme interação entre as pessoas, inclusive de modo praticamente anônimo" (NETTO, 2017, p. 407). Dividimos essas agressões verbais em duas categorias porque injuriar é ofender alguém utilizando "elementos referentes a raça, cor, etnia, religião, origem ou a condição de pessoa idosa ou portadora de deficiência", ao passo que difamar está delimitado como 
imputar a alguém "fato ofensivo à sua reputação" (BRASIL, 2019). Ambos os crimes têm penas diferenciadas, sendo que a injúria tem pena maior.

Do ponto de vista do valor semântico das expressões "injúria" e "insulto na linguagem comum", devemos considerar, para efeito de nossa análise, ainda, que injúria deriva de injustiça, de ações contrárias ao direito do outro. Nesse sentido, a injúria racial, prática que interessa a este estudo, constitui, ainda que ocorra apenas no plano verbal, crime de violação de direito do outro. A origem etimológica desse termo, inclusive, conforme informa o Grande Dicionário Houaiss (2019), está associada a "injustiça, agravo, dano", podendo ter, inclusive, o sentido ampliado para danos físicos, em determinados contextos. Já o insulto, etimologicamente ligado ao sentido de "saltar sobre, pular", segundo o mesmo Grande Dicionário Houaiss (2019), vincula-se mais frequentemente a danos morais que, nem sempre, vinculam-se à violação de direitos materiais do outro e sim morais.

\section{OS ATOS DE FALA: PERFORMATIVIDADE, VALOR ILOCUCIONÁRIO E INTENCIONALIDADE}

Searle (1984, p. 26) afirma que "falar uma língua é executar atos de fala," tais como fazer afirmações, perguntas, promessas, dar ordens referir e predicar. Afirma, ainda, que "esses atos são, em geral, possíveis graças a certas regras” (SEARLE, 1984, p. 26). Austin (1990, p. 24) categoriza certos enunciados como "Eu batizo", "Eu aposto", "Aceito esta mulher ou este homem como esposa ou marido", entre outros, como aqueles que, ao serem proferidos em circunstâncias apropriadas, não têm função descritiva nem declarativa, são atos performativos que não podem ser considerados verdadeiros ou falsos, mas estão sujeitos a certas condições de felicidade que, se preenchidas, transformam esses enunciados em dizeres que constituem fazeres ou atos de fala.

Entre as condições de felicidade desses atos estão a convencionalidade, que se encontra na base da aceitação deles como performativos, bem como o fato de serem proferidos por pessoas autorizadas a proferi-los em circunstâncias adequadas (AUSTIN, 1990, p. 31). Além disso, Austin (1990) categoriza os graus de performatividade desses atos de fala ou atos de linguagem em: performativos puros, quase-performativos, enunciados intermediários e performativos implícitos.

Performativos puros são enunciados expressos em primeira pessoa, como "Aposto x", "Juro y", "Agradeço a z". Quando se altera o tempo verbal, altera-se o grau de performatividade do ato de fala. Esse processo transforma os performativos em declarativos, tira-lhes, por assim dizer, a performatividade, como se pode observar em: "Ele apostou x", "Ele jurou y", "Ele agradeceu a z".

Os quase-performativos constituem outra categoria dos atos de fala que são reduzidos. O juiz pode proferir o enunciado "Culpado!" em vez de "Eu declaro o réu culpado". Os quaseperformativos admitem também o acréscimo de um modalizador ou de outro prefixo: "Gostaria de 
convidá-lo a comparecer à cerimônia x". É necessário fazer uma análise do contexto em que são proferidos os enunciados para que se possa inferir o valor performativo deles. Nos quaseperformativos, "o verbo introdutor deve ser considerado um simples prefixo suavizador" (KERBRAT-ORECCHIONI, 2005, p. 23).

Os enunciados intermediários são parecidos com as fórmulas puramente performativas, ainda que não denominem de forma explícita aquilo que performam, como nos casos de "Eu sou eternamente grato a você" ou "Eu sinto muito", que, na prática, performam um agradecimento e um pedido de desculpas, respectivamente. No primeiro caso, o ato de agradecer é intensificado pelo advérbio "eternamente"; no segundo, o pedido de desculpas é intensificado também pelo "muito" pesar que o próprio locutor causou a si mesmo quando ofendeu ou insultou o interlocutor, pesar que parece evocar o desejo de dividir solidariamente com o outro a dor infligida a ele. Pelo modo como são produzidos, estes enunciados estariam entre os constatativos, enunciados que relatam estados de coisas, e os performativos, que realizam o que dizem (KERBRAT-ORECCHIONI, 2005, p. 23).

No quarto caso, o dos performativos implícitos, ao formular uma declaração como "Eu ordeno que você vá embora", o locutor pode realizar o ato de ordenar implicitamente, quer dizer, por meio da elipse do verbo "ordenar" em um enunciado como: "Vá embora". Esses performativos implícitos ou primários são dotados de força ilocucionária ou valor ilocucionário, que é outro aspecto a ser considerado na análise dos atos de linguagem, pois constitui uma problemática mais geral do fenômeno, no dizer de Kerbrat-Orecchioni (2005, p. 25).

A "força ilocucionária" dos enunciados emerge de uma das três dimensões por meio das quais os atos da fala podem ser analisados. A dimensão locucionária diz respeito à propriedade do ato segundo as normas de determinada língua; a ilocucionária caracteriza um ato que realiza a ação denominada pelo enunciado: promessa, juramento, ordem, pedido, batismo, injúria, insulto. O adjetivo perlocucionário caracteriza o efeito do ato sobre o ouvinte, como intimidar ou convencer, injuriar e insultar, por exemplo. Esse efeito depende, fundamentalmente, da situação da enunciação (AUSTIN, 1990).

Para este estudo, não nos deteremos no inventário dos verbos que classificam os diferentes atos, uma vez que eles são sempre abertos, tampouco nas condições necessárias para a efetivação deles, pois nosso interesse está em verificar a "força ilocucinária" ou o "valor ilocucionário" de enunciados carregados de intencionalidade que realizam os atos de violência verbal estudados aqui: a injúria e o insulto.

Neste ponto, é necessário considerar a questão da intencionalidade e sua natureza na construção dos atos de linguagem: "não só devemos supor o ruído ou a marca [dos enunciados] como 
produzidos por um comportamento intencional, mas também que estas intenções são de uma natureza muito especial, particular aos atos de fala" (SEARLE, 1984, p. 27).

Vale dizer que se o falante tem a intenção de produzir um dado efeito ilocucional, como uma promessa, por exemplo, ele precisa que o enunciado produza no ouvinte a percepção de que ele, o falante, tem a intenção de cumprir a promessa, o que distingue este ato de fala de um enunciado que expressasse o mero desejo de fazer algo (SEARLE, 1984, p. 81). Desse modo, a intenção de ferir o outro é própria da injúria verbal porque o falante tem a intenção de fazer o seu interlocutor sentir-se agredido. A intenção do insulto é a de estigmatizar o insultado com a intenção, muitas vezes, de isolálo da sociedade.

Cabem aqui também algumas considerações sobre os atos de linguagem indiretos, aqueles que realizam atos de violência verbal por diferentes formulações, como certas injúrias e insultos. Dizer que um ato de linguagem é indireto significa afirmar que "um mesmo valor ilocucionário pode manifestar-se através de um grande número de realizações diferentes" (KERBRAT-ORECCHIONI, 2005, p. 47).

Também pode ocorrer o oposto, pois "uma mesma estrutura pode expressar valores ilocucionários diversos. A frase 'Está fazendo uma corrente de ar' pode, dessa forma, exprimir uma constatação, uma reclamação, uma solicitação e até mesmo tudo isso ao mesmo tempo [o que implica que] a maioria das estruturas frasais são, no nível da língua, ilocutoriamente polissêmicas" (KERBRAT-ORECCHIONI, 2005, p. 48) e que a forma como é construído o enunciado é regulado estrategicamente pelo locutor de modo que produza o efeito desejado em seu interlocutor.

Nas práticas de violência verbal são comuns os atos de linguagem com valor ilocucionário de injúria e de insulto, mas, em grande parte dos casos, a formulação desses atos dá-se por meio de marcadores que o dissimulam ou compensam a impossibilidade de empregar performativamente o insulto em formulações como "Eu declaro que você é x" seguido de um xingamento. Geralmente, são produzidos apenas como " $\mathrm{x}$ ", dito para o interlocutor ou para um terceiro. Essas práticas estão ligadas a rituais de preservação das faces, conforme veremos adiante.

\section{A CONSTRUÇÃO E A PRESERVAÇÃO dAS FACES NAS INTERAÇÕES PESSOAIS}

Goffman (2011, p. 13-14) conceitua fachada ou face como "o valor social positivo que uma pessoa efetivamente reivindica para si mesma através da linha que os outros pressupõem que ela assumiu durante um contato particular. A fachada é a imagem do eu delineada em termos de atributos sociais aprovados". 
Linha, por sua vez, é compreendida como um "padrão de atos verbais ou não verbais com o qual [uma pessoa] expressa sua opinião sobre a situação, e através disso sua opinião sobre os participantes [em contatos face a face ou mediados por outras pessoas], especialmente ela própria" (GOFFMAN, 2011, p. 13).

Goffman afirma, ainda, recorrendo a um conceito da psicanálise, que a pessoa catexiza sua face, quer dizer, investe energia mental ou emocional na representação dela. Esse investimento leva em conta as condições específicas das interações, vale dizer, a situação de comunicação em que são ou não institucionalmente legitimados certos dizeres e fazeres. A manutenção da face deve levar em consideração, além da própria face, “a posição da pessoa em seu mundo social” (GOFFMAN, 2011, p. 15).

Esse ritual social de manutenção e de preservação da face envolve categorias de sentimentos, como o orgulho, derivado de atos de manutenção da face pelo dever da pessoa a si mesma; a honra, sentimento derivado de atos de manutenção da face pelo dever social a questões mais amplas; e a dignidade, sentimento derivado de atos de manutenção da face ligados à postura (GOFFMAN, 2011, p. 17-18). Ocorre que, mesmo sendo algo pessoal e centro da segurança e prazer do indivíduo, "a fachada constitui um empréstimo da sociedade, ela será retirada a não ser que a pessoa se comporte de forma digna dela" (GOFFMAN, 2011, p. 18), o que torna cada homem carcereiro de si mesmo.

\begin{abstract}
Assim como esperamos que um membro de qualquer grupo tenha respeito próprio, também esperamos que ele mantenha um padrão de consideração, esperamos que ele realize certos esforços para resguardar os sentimentos e as fachadas dos outros presentes, e esperamos que ele faça isso voluntária ou espontaneamente por causa de uma identificação emocional com outros e com os sentimentos deles. Como consequência, ele não estará inclinado a testemunhar a desfiguração [defacement] dos outros. Em nossa sociedade, chamamos de 'sem-coração' uma pessoa que consegue testemunhar a humilhação de outra mantendo impassivelmente um semblante frio, assim como aquela que consegue impassivelmente participar de sua própria desfiguração é considerada 'sem-vergonha' (GOFFMAN, 2011, p. 18).
\end{abstract}

As estratégias de preservação da fachada constituem modos de "tornar o que quer que esteja fazendo consistente com a fachada" (GOFFMAN, 2011, p. 20) e, entre elas, está a polidez que se manifesta, entre outros modos, em grande medida por meio da linguagem.

Goffman (2011, p. 15) afirma que "apesar de a preocupação com a fachada enfocar a atenção da pessoa na atividade em curso, ela deve, para manter a fachada nessa atividade, levar em consideração seu lugar no mundo social além dela”. Pode-se dizer que, nas interações face a face, a prospecção, ou seja, a perspectiva de um novo encontro futuro faz com que a pessoa procure manter a face uma vez que ela teme que o fato de não conseguir conservá-la na presente situação fará com 
que os outros possam tomar isso como um sinal "de que não precisarão demonstrar consideração pelos seus sentimentos no futuro" (GOFFMAN, 2011, p. 15).

Sob a perspectiva dos atos de linguagem que desconstroem a face alheia ou preservam a própria face, encontramos importantes contribuições em Brown e Lewinson (1987) que retomam e redimensionam o conceito de fachada ou face de Goffman.

Our notion of 'face' is derived from that of Goffman [...] and from the English folk term, which ties face up with notions of being embarrassed or humiliated, or 'losing face'. Thus face is something that is emotionally invested, and that can be lost, maintained, or enhanced, and must be constantly attended to in interaction. In general, people cooperate (and assume each other's cooperation) in maintaining face in interaction, such cooperation being based on the mutual vulnerability of face. (BROWN; LEVINSON, 1987, p. 61) ${ }^{3}$.

A tentativa de manutenção da face decorre da pressuposição de que todo membro adulto competente de uma sociedade tem e sabe que o outro tem uma autoimagem pública que reivindica para si mesmo, a qual, por sua vez, possui dois aspectos: (a) face negativa: a reivindicação básica de territórios, reservas pessoais, direitos de não interferência, liberdade de agir e de se impor frente aos outros; e (b) face positiva: a autoimagem consistente ou a "personalidade" que o indivíduo deseja que seja apreciada, aprovada e reivindicada como adequada pelos demais. Também estão incluídas nesta pressuposição certas capacidades racionais, em particular, modos consistentes de raciocínio, que avaliam os fins desejados e os meios que serão empregados para alcançá-los (BROWN; LEVINSON, 1987, p. 61). Inferimos que essas capacidades racionais podem ser avaliadas nos enunciados, entre outras formas, por meio das marcas de intencionalidade dos dizeres. No caso da restauração da face negativa, as estratégias empreendidas revelam o desejo do indivíduo de que suas ações não sejam impedidas pelos outros, o desejo de preservação do território; no caso da manutenção da face positiva, as ações refletem o desejo do indivíduo de ser desejável para os outros, ou pelo menos para parte de algum grupo.

Kerbrat-Orecchioni (2017, p. 21) afirma que o modelo brown-levinsoniano da polidez linguística "repousa inteiramente sobre as noções de 'território' e de 'face', rebatizadas por Brown e Levinson de 'face negativa' e 'face positiva', o que lhes permite construir a noção genérica de 'ato ameaçador para a(s) face(s)' (Face Threatening act ou FTA)".

\footnotetext{
${ }^{3}$ Nossa noção de 'face' deriva da [noção] de Goffman [...] e do termo popular inglês, que se vincula a noções de ser envergonhado ou humilhado ou "perder a cara". Assim, o rosto é algo que é emocionalmente reservado, que pode ser perdido, mantido ou aprimorado e que deve ser constante objeto de preocupação em interações. Em geral, as pessoas cooperam (e assumem a cooperação recíproca) para manter a face na interação, sendo essa cooperação baseada na vulnerabilidade mútua do rosto. (Tradução dos autores). No português, o termo popular referido é "quebrar a cara".
} 
[...] a maioria dos atos de fala que realizamos ao longo de nossa vida cotidiana é potencialmente ameaçadora para tal ou tal face presente, o que vem contrariar o 'desejo' universal ou 'necessidade de face' (face want), e gera um risco sério para o desenvolvimento da interação. É então que intervém o 'trabalho de face' (face-work) (KERBRAT-ORECCHIONI, 2017, p. 21).

Nesse sentido, Kerbrat-Orecchioni (2017, p. 21-22) aponta que Brown e Levinson cruzam os conceitos de Searle e Goffman ao "'reciclar a noção de ato de fala', examinando esses atos segundo os efeitos que eles podem ter sobre as faces das partes presentes, tornando essa noção [...] apta a servir de base para uma teoria nova da polidez" e também da impolidez.

Acresce à análise dos efeitos desses atos a leitura dos atenuadores, termos "que a língua coloca generosamente à nossa disposição, a fim de que possamos 'polir' as arestas demasiadamente afiadas dos FTAs que somos levados a cometer, tornando-os menos agressivos para as faces delicadas de nossos parceiros de interação (KERBRAT-ORECCHIONI, 2017, p. 22).

Ao tratar das estratégias para produzir FTAs, Brown e Levinson (1987) consideram duas situações relativas à intenção comunicativa. Numa delas, o ator ou indivíduo produtor do FTA performa esse ato de linguagem em público, caso considere que as testemunhas concordariam inequivocamente com aquilo que elas dirão. Neste caso, há duas subcategorias de atos: um tipo que poderá será descoberto e não reparativo da face própria ou alheia; e outro tipo que poderá ser de ação reparadora da face própria ou alheia, com marcas tanto de polidez quanto de impolidez.

Em outra situação, caso o indivíduo tenha receio de se comprometer com alguma proposição que não seja unânime entre os interlocutores, ele performa um FTA de modo dissimulado, servindose de ironia, eufemismo ou pergunta retórica, por exemplo.

Esse modelo teórico abre espaço para uma segunda categoria de atos de fala, os Face Flattering Acts (FFAs) ou Face Enhancing Acts, atos para preservar, restaurar ou melhorar a face do outro e de si. Desse modo, todo ato de fala pode, portanto, ser descrito como um FTA, um FFA ou um complexo desses dois componentes. (KERBRAT-ORECCHIONI, 2017, p. 23).

Com base nessas categorias, procuraremos analisar dois casos que evolvem injúria e insulto por meio de FTAs que foram mais ou menos violentos em função das circunstâncias em que foram produzidos e que empreenderam uma série de complexas estratégias de trabalho de face (face-work). Um deles ocorreu em público, no estádio de futebol de Belo Horizonte "Mineirão", em 3/11/2019, e foi publicado pelo portal de notícias GloboEsporte.com (GLOBOESPORTE.COM, 2019), cuja ligação disponibilizamos por meio das referências deste artigo; e o outro foi registrado em comentários do site Tvefamosos, do Portal Universo on-line, UOL, em 11/11/2019 (DIAS, 2019), cuja ligação também pode ser acessada pelas referências deste artigo. O critério que norteou a escolha de materiais sobre diferentes temas, futebol e vida de celebridades pautou-se no fato de que ambos 
os casos de violência verbal são exemplos peculiares de fatos do universo da Internet e só tiveram repercussão em virtude das formas de interação dessa mídia e do alcance que ela tem, aspectos que serão levados em conta na análise que faremos mais adiante.

\section{A INJÚRIA E A RETRATAÇÃo PERFORMADAS COMO ATO DE FALA INDIRETO E A PRESERVAÇÃo DA FACE}

Recentemente, torcedores praticaram injúria racial contra um segurança que trabalhava no jogo entre Cruzeiro e Atlético mineiro, em 3/11/2019, no estádio do Mineirão, em Belo Horizonte. Segundo a notícia, o produtor do FTA estava tentando ultrapassar um setor do campo, vale dizer, estava tentando apropriar-se de um território interditado e foi contido pelo segurança. $\mathrm{O}$ ato de linguagem teve como objetivo restaurar a face do agressor que se sentiu humilhado pelo tolhimento de um direito que ele acreditava ter e, por isso, reivindicou-o para si. Essa reivindicação do território ameaçado deu-se por meio da violência verbal materializada em um FTA que agrediu a face do segurança.

No vídeo, em meio a uma discussão, um dos torcedores diz para o segurança: "Você pôs a mão em mim, olha sua cor"4 . Na primeira parte do enunciado, um típico FTA público sem intenção reparadora, a declaração "Você pôs a mão em mim", na prática, performa uma ordem: "Tire a mão de mim". Já o valor performativo da ordem do enunciado seguinte, "Olha a sua cor", declara indiretamente que pessoas que têm a mesma cor do interlocutor, do segurança no caso, não têm poder ou autoridade sobre pessoas que têm a cor do falante, ainda que estejam exercendo institucionalmente uma atividade que lhes permitiria, em tese, conter os excessos dos outros fisicamente.

Diante da repercussão negativa e do processo policial que foi instaurado, o agressor produziu um FFA à imprensa cuja função seria a de polir o ato de linguagem anterior falando, agora, para um público diferente do público que presenciou o insulto:

Eu não sou racista. Estou arrependido por aquilo que eu falei. Falei num momento de ânimos exaltados na hora do jogo. Quero pedir perdão a ele, por todos os insultos que eu fiz, pelo cuspe que eu proferi. Aquilo não é da minha índole. Sou um pai de família, crio minhas filhas para respeitar todos os seres humanos. Se tiver uma oportunidade, pessoalmente, quero pedir perdão a ele pelo meu ato, naquele momento 5 .

\footnotetext{
${ }^{4}$ Disponível em: https://globoesporte.globo.com/mg/futebol/noticia/seguranca-do-mineirao-e-alvo-de-injuria-racial-detorcedor-apos-cruzeiro-X-atletico-mg-olha-sua-cor.ghtml. Acesso em: 14 nov. 2019.

${ }^{5}$ Disponível em: https://globoesporte.globo.com/mg/futebol/noticia/suspeitos-falam-em-animos-exaltados-apos-ato-deinjuria-racial-e-querem-pedir-de-perdao-a-seguranca-do-mineirao.ghtml. Acesso em: 14 nov. 2019.
} 
Na defesa que fez de si próprio, é relevante notar certa consciência que o agressor tem da força ilocucionária do ato de linguagem que produziu no momento da agressão. Essa consciência está inscrita na impropriedade linguística, no lapso verbal, da declaração que ele deu quando disse que "fez" insultos e que "proferiu” o cuspe, uma vez que, logicamente, cuspir é uma ação física, e proferir é um ato de linguagem. Insultar é, na declaração do indivíduo, algo que atinge concretamente o interlocutor, como um cuspe.

A estratégia de retratação do injuriador, da perspectiva dos atos de linguagem, pode ser dividida em dois momentos: um em que se retrata à sociedade da injúria e outro em que se retrata ao indivíduo. O primeiro é constituído por um ato de linguagem implícito; o segundo, por meio de um quase performativo.

Apesar de declarar-se arrependido, o injuriador elege como atenuante para a agressão as circunstâncias da "hora do jogo", em que "os ânimos exaltados" interferem no comportamento das pessoas. Quanto a esse aspecto, é relevante uma reflexão sobre as circunstâncias que envolvem certos atos de linguagem, notadamente a injúria. A sensação de estar protegido por um grupo e não poder ser identificado torna as pessoas mais corajosas para fazerem o que não fariam se soubessem que estão sendo monitoradas. No caso dos comentários na Internet, essa sensação também pode advir da sensação de anonimato que as redes de computador transmitem a quem está no ambiente virtual, como analisaremos mais à frente.

Voltando ao enunciado em questão, em primeiro lugar, o agressor admite ter praticado injúria como parte de um grupo e contra outro grupo, o dos que têm a mesma cor da vítima, e pretende que essa injúria seja mitigada por meio da retratação à sociedade. Para tanto, formula um ato de linguagem indireto, uma vez que, ao declarar ser "pai de família", disposto a ensinar às filhas o respeito a "todos os seres humanos", o sujeito apela para o senso comum que considera o ambiente familiar, por princípio, virtuoso e oposto ao ambiente não familiar de um estádio de futebol em que os “ânimos exaltados” justificariam agressões. Nesse primeiro momento da fala, o pedido de desculpas é performado por meio de um enunciado intermediário: "Estou arrependido por aquilo que eu falei”, ato que não denomina de forma explícita aquilo que realiza. Aqui o enunciador elege como interlocutor a sociedade em geral, aquela mesma sociedade patriarcal que deveria reconhecer o valor intrínseco de um "pai de família". Vale dizer: a retratação à classe do injuriado e àqueles da sociedade que repudiam o racismo deve ter sucesso, segundo o locutor, porque um "pai de família" que "cria filhas para respeitar todos os seres humanos" deve ter certo salvo-conduto quando comete injúrias em certas circunstâncias, uma vez que o dano causado à sociedade foi menor que o benefício que presta continuamente a essa mesma sociedade. 
Num segundo momento, esse mesmo ato de pedir desculpas é realizado por meio de um quase-performativo que indica uma intencionalidade com acréscimo de um modalizador: "Se tiver uma oportunidade, pessoalmente, quero pedir perdão a ele pelo meu ato, naquele momento". Tratase, agora, da formulação do desejo de se retratar face a face com o agredido, pessoalmente. A função do modalizador, "Se tiver uma oportunidade", neste caso, condiciona o sucesso do FFA à disposição da vítima para ouvi-lo. A circunstância do ato, "naquele momento" (o dos ânimos exaltados), tem a função de reforçar a excepcionalidade do ato de linguagem e, portanto, minimizar a gravidade dele.

No caso em análise, essa estratégia complexa do trabalho de face do agressor verbal tem como finalidade a preservação da face dele ancorado tanto no passado quanto no futuro. Ele invoca o passado ao dizer que não tem tradição de agressor, "Aquilo não é da minha índole”; invoca o futuro tentando salvar a sua reputação quando as filhas crescerem, "Sou um pai de família, crio minhas filhas para respeitar todos os seres humanos". Não quer, enfim, ser reconhecido como um "sem coração".

\section{O INSULTO NOS COMENTÁRIOS DAS NOTÍCIAS NA INTERNET}

No caso da violência verbal, notadamente nos casos que dizem respeito a comentários sobre celebridades cujas atitudes o locutor considera reprováveis, a estratégia para impor os valores passa pela tentativa de destruir a face positiva da celebridade por meio da injúria e do insulto, FTAs formulados como atos de linguagem indiretos que têm, em muitos casos, a função de excluir o agredido da sociedade funcionando, em certo sentido, como anátemas. Essa formulação consiste em declarações que, muitas vezes, não explicitam os performativos, mas os invocam por meio de impolidez. Aqui, raramente encontramos FFAs que equilibrariam os FTAs, pois raramente os detratores têm de prestar contas à sociedade pelo que dizem.

Num passado recente, falar mal do comportamento de determinada celebridade constituía uma prática restrita a pequenos grupos reunidos em ambientes também pequenos. Hoje, o espaço virtual ampliou essas vozes e deu a elas a sensação de estarem falando diretamente àquelas celebridades que são objetos das matérias jornalísticas, só que também se sentem protegidas pelo anonimato. Essas falas, geralmente, materializam valores que o sujeito acredita serem prestigiados pela sociedade. Aqui, as bandeiras e as camisas das agremiações, que são os emblemas que aglutinam a torcida e dão força ao indivíduo para insultar o adversário ou qualquer outro que se coloque como barreira às suas ações nos estádios de futebol, são substituídas por enunciados que apelam para o senso comum e que condenam certos comportamentos pouco aceitos em sociedades ultraconservadoras, como relações homossexuais, relações extraconjugais, liberdade sexual, igualdade de gênero entre outros. A violência verbal materializada pelos atos de linguagem violentos, 
os FTAs, tem como objetivos desconstruir a face da celebridade, reivindicar para o agressor verbal um certo território moral e conferir-lhe a categoria de guardião dos valores tradicionais do grupo que ele considera que devam ser ou que são universalmente aceitos.

Para analisar essa categoria de FTAs, selecionamos comentários feitos ao pé da nota "Camila Pitanga assume namoro de um ano com a artesã Beatriz Coelho", assinado pelo comentarista Leo Dias, publicada no site Tvefamosos, do Portal Universo on-line, UOL, em 11/11/20196.

O texto dá conta de informar que Camila Pitanga [atriz brasileira] está namorando a artesã Beatriz Coelho e que o relacionamento foi confirmado pela assessoria de imprensa da atriz, a qual já mantinha esse relacionamento há um ano. O texto informa, ainda, que a atriz já teve pelo menos dois relacionamentos heterossexuais e, em seguida, divulga uma peça dela que está em cartaz, bem como informa sobre um trabalho futuro que a atriz fará para a televisão.

Selecionamos alguns dos comentários, todos FTAs executados com o objetivo de preservar o território dos indivíduos que, de algum modo, sentem-se violados pelas práticas que consideram reprováveis do ponto de vista religioso:

(1) Os tempos mudaram, acabaram os encantos, o pai, a mãe, os filhos não vem (sic) mais de genitores: são encomendados como enlatados, já previstos a (sic) muito tempo em relatos bíblicos.

(2) Vou ter que procurar logo logo um planeta hétero e espiritualista pra viver...ou desencarnar logo. O último apague a luz...

(3) Eu e meus amigos, todos cristãos do Apocalipse, estamos construindo uma Fortaleza Santificada. Lá, todos viverão segundo as leis da Cimitarra Oriental.

(4) A Globo (que tem esse nome não à toa; vide globalismo) implanta a perversão da família e dos valores morais cristãos na sociedade brasileira. Ela quer destruir o núcleo familiar e usa seus empregados para fazer propaganda de suas sevícias e mazelas.

(5) Esse pessoal é ligado em sexo. Não buscam um companheirismo, uma família, laços construtivos. E sexo por sexo, tudo vale !! (sic) ${ }^{7}$.

A homossexualidade é considerada pelos produtores dos FTAs anteriores uma prática capaz de destruir a sociedade de modo que o indivíduo que está em um relacionamento dessa natureza, de algum modo, irá causar o fim dos tempos pelas suas ações que ferem a "espiritualidade" (2); “destroem o núcleo familiar" (4), tão valorizado pelo agressor do Mineirão, como vimos, ou são movidas apenas pelo prazer (5), sexo que não visa à reprodução $(5,1)$. No caso do fragmento (4), inclusive, o locutor imputa equivocadamente à atriz a prática de um ato de "sevícia", que significa "tortura", crendo talvez que essa palavra seja, se levarmos em conta a ideologia aparentemente

\footnotetext{
${ }^{6}$ Disponível em: https://tvefamosos.uol.com.br/colunas/leo-dias/2019/11/11/camila-pitanga-esta-namorando-a-artesabeatriz-coelho-ha-um-ano.htm. Acesso em: 14 nov. 2019.

${ }^{7}$ Disponível em: https://tvefamosos.uol.com.br/colunas/leo-dias/2019/11/11/camila-pitanga-esta-namorando-a-artesabeatriz-coelho-ha-um-ano.htm. Acesso em: 14 nov. 2019.
} 
ascética do produtor do FTA, sinônimo de "devassidão". Neste sentido, ele está em consonância com o que pensa o produtor do FTA (5), embora tenha empreendido uma seleção lexical incoerente. A invocação do ascetismo como pressuposto moral aceitável situa os produtores desses atos de linguagem em um território de bons cristãos no qual não devem ser aceitos os que aprovam as práticas dos agredidos, considerados vilões: "um planeta hétero" (2); o espaço dos desencarnados (2); uma "Fortaleza Santificada" (3). Esses espaços são todos referenciados metonimicamente em (4), como sendo a "sociedade brasileira" desejada, uma sociedade seguidora "dos valores morais e cristãos".

O objetivo comum dos FTAs é excluir o outro da sociedade, por meio de atos de linguagem indiretos, uma vez que nenhum deles menciona a atriz em questão, mas falam genericamente desse “pessoal” (5) ou da Globo (4), empresa em que atriz trabalha. Neste sentido, a condição de celebridade da pessoa atacada faz com que os insultos sejam dirigidos não só a ela, mas a qualquer indivíduo que se identifique com os valores dela, assim, como agente institucional de uma corporação que usa os empregados para estimular "mazelas", falhas morais. Entre essas falhas estaria não só a relação homoafetiva da atriz, mas também qualquer relação homoafetiva.

Esses FTAs explícitos, com intenção de destruir a face alheia, são construídos por meio de atos de linguagem implícitos que não dizem "Eu declaro que os homossexuais sejam excluídos da sociedade", mas os apresenta como indivíduos perniciosos aos valores, que estariam dominando o território moral tanto dos bons homens quanto dos bons valores. Isso faz desses FTAs, portanto, tentativas de recuperar o território que os agressores acreditam que estão perdendo.

Outros aspectos são, ainda, apontados como negativos na relação homoafetiva da atriz:

(6) Mais uma que é levada pela modinha. O que antes era uma simples opção, hoje se tornou tendência. Guerreiros, avante! Vamos preservar as remanescentes!

(7) O que está acontecendo conosco; o que restou dos chamados héteros? Será que virou modinha esse negócio de assumir homossexualidade.... mulher com mulher virou um festival...........só nos últimos meses já contabilizei mais de dúzia de mulheres lindas declarando estar com outra. Seria uma forma de chamar os holofotes para as carreiras talvez já decadente? Tempos negros para nós héteros.

(8) Mais uma que não gosta do sexo oposto. Esta (sic) virando moda, faço votos que não façam essa atitude obrigatória. UMA VERGONHA o que tem acontecido com a raça humana. Chego a (sic) conclusão que é a única irracional

(9) Eu ultimamente estou sendo discriminado por ser HETEROSEXUAL.

(10) O que está acontecendo? É impressionante a quantidade de mulheres que se dizem adeptas e enaltecem as maravilhas resultante da fricção entre bombrils (sic). Do outro lado, o surgimento em massa de novos padeiros também tem sido inacreditável ${ }^{8}$.

\footnotetext{
${ }^{8}$ Disponível em: https://tvefamosos.uol.com.br/colunas/leo-dias/2019/11/11/camila-pitanga-esta-namorando-a-artesabeatriz-coelho-ha-um-ano.htm. Acesso em: 14 nov. 2019.
} 
Nesta segunda série de comentários prevalece o caráter superficial atribuído à relação da atriz, estendido a todas as outras relações do gênero: "Mais uma que é levada pela modinha" (6); "Será que virou modinha esse negócio de assumir homossexualidade” (7); "Está virando moda" (8).

Essa suposta moda apontada pelos internautas parece ameaçar o território dos produtores dos insultos a ponto de eles convocarem os pares para combater o homossexualismo por meio de FTAs explícitas, formuladas por atos de linguagem indiretos, a saber: (a) ordem implícita que disfarça a formulação "Sigam-me” no enunciado "Guerreiros, avante!" (7); (b) declaração que assume valor ilocucional de convocação no enunciado "Tempos negros para os héteros" (8); (c) desejo modificado por modalizador que tem a função de fragilizar o locutor em face do grupo que ameaça a sua face: "faço votos que não façam essa atitude obrigatória" (8); (d) enunciado constatativo com valor performativo de declarar que os discriminados é que são os discriminadores: "estou sendo discriminado por ser heterossexual" (9); e (e) pergunta que assume o valor performativo de se declararem anormais as relações homoafetivas tanto por meio da indignação com que é formulada quanto pelos comentários sarcásticos que a sucedem: “O que está acontecendo?...”(10). Neste último caso, a crítica à homossexualidade é direcionada também ao universo masculino.

As condições de sucesso desses FTAs, quer dizer, as circunstâncias que os tornam performativos, são parecidas com as circunstâncias que envolveram o caso da agressão ao segurança no estádio de futebol. Envolvidos pela presença física ou pela força ideológica dos pares, o sujeito produz enunciados que não produziria, caso tivesse dúvidas sobre a opinião dos outros a respeito das suas ideias. No caso da Internet, no evento em análise, não houve retratação ou FFA por parte dos agressores, pois os comentários feitos não ganharam a dimensão que ganhou a injúria racial filmada no Mineirão.

\section{CONSIDERAÇÕES FINAIS}

As propriedades das interações pessoais coletivas em grandes eventos, como um jogo de futebol ou em interações virtuais de caráter aberto (como os comentários de notícias), em certa medida, criam oportunidades para que os locutores ignorem fórmulas de preservação da face positiva que, geralmente, usariam em interações face a face. Essas circunstâncias deixam-nos à vontade para reivindicarem a posição de porta-vozes de valores nem sempre civilizados, que eles consideram prestigiados ou que acreditam que deveriam ser prestigiados pela maioria dos leitores dos seus enunciados. Para a compreensão desse fenômeno, é necessário articular o conceito de atos de linguagem, notadamente os indiretos, e algumas de suas propriedades à questão da construção e da preservação da fachada ou face, conceito de Goffman, como forma de compreender como o equilíbrio 
interacional tende a ser perdido nessas situações, mais até na Internet do que nos estádios de futebol, como vimos nos casos estudados neste trabalho, pois a injúria do Mineirão exigiu reparação, enquanto os insultos à atriz provavelmente cairão no esquecimento.

Os atos de linguagem com valores ilocucionários de injúria e de insulto são muito comuns em ambientes coletivos e em comentários de notícias da Internet porque esses ambientes proporcionam interações com características próprias em relação às interações face a face do dia a dia. As possíveis causas disso podem ser compreendidas sob, pelo menos, três aspectos.

Primeiramente, os interlocutores sentem-se protegidos de algum modo: no caso dos torcedores, o grupo que integram os protege do grupo adversário, dando-lhes sensação de força que se materializa, muitas vezes, nos atos de linguagem e em seu valor ilocucionário. Vale dizer que o fato de acreditar que as testemunhas aprovam integralmente o que diz encoraja a produção de um FTA explícito, com intenção de destruir a face alheia. No caso da Internet, os indivíduos sentem-se protegidos atrás da tela de um aparelho eletrônico, mas talvez este não seja o fator mais importante que os condicionam a produzirem FTAs violentos.

Em segundo lugar, com um peso maior, há o fator de os indivíduos que participam de interações virtuais não contarem com a possibilidade de se encontrarem no futuro com suas vítimas. Certa sensação de efemeridade das relações estimula as pessoas a praticarem certos atos de linguagem violentos que não ousariam praticar se soubessem que teriam de se encontrar novamente com os agredidos.

Em terceiro lugar, os grupos de torcedores em estádios de futebol sentem-se à vontade para ofender o grupo adversário, os jogadores, os juízes e os auxiliares em campo porque a voz desses torcedores faz coro com a dos parceiros. Do mesmo modo, os internautas também se sentem à vontade para dizerem o que dizem porque acreditam que seus valores são compartilhados ou deveriam ser compartilhados pela voz da sociedade com a qual acreditam estar fazendo coro. Esse fenômeno, a manifestação da violência verbal em um coro que acredita ser uníssono, possibilita inclusive, em certo sentido, que possamos mensurar os níveis de preconceito de uma sociedade, bem como permite uma análise dos mecanismos dos atos de linguagem, quer dos que procuram a ofensa, que dos que procuram a retratação.

Ao mesmo tempo que o futebol tem a função de agregar as pessoas de diferentes classes sociais, de promover amizades e de unir o país em alguns casos, esse esporte reflete, tanto em campo quanto na torcida, aspectos negativos da sociedade, como o racismo, que segrega pela cor da pele as pessoas. A Internet é uma ferramenta de integração social porque conecta de modo bastante eficiente as pessoas. Contudo, ela pode ser, também, mais um meio de exclusão que se dá, em grande medida, pelos atos de linguagem indiretos que constituem modos de reprovação enérgica, condenação, 
repreensão, maldição, execração de certos indivíduos ou grupos. Esse efeito colateral da rede de computadores, por assim dizer, materializa-se nos comentários ao pé dos textos feitos pelos leitores em notícias sobre celebridades. Espaços democráticos em princípio, como os estádios de futebol e a rede de computadores, dão poder aos locutores para exercer a tirania por meio da violência verbal.

\section{REFERÊNCIAS}

AUSTIN, J. L. Quando dizer é fazer: palavras e ação. Porto Alegre: Artes Médicas, 1990.

BRASIL. Código Penal. Disponível em: https://www.planalto.gov.br/ccivil_03/decretolei/del2848.htm. Acesso em: 14 nov. 2019.

BROWN, P.; LEVINSON. S. C. Politeness Some universals in language usage. New York: Cambridge University Press, 1987.

DIAS, L. Camila Pitanga assume namoro de um ano com a artesã Beatriz Coelho. TvUOL Universo On-line, 20 de nov. de 2019. Disponível em: https://tvefamosos.uol.com.br/colunas/leodias/2019/11/11/camila-pitanga-esta-namorando-a-artesa-beatriz-coelho-ha-um-ano.htm. Acesso em: 14 nov. 2019.

GLOBOESPORTE.COM. Segurança do Mineirão é alvo de injúria racial de torcedor após Cruzeiro x Atlético-MG: "Olha sua cor". GloboEsporte.com, Belo Horizonte, 10 de nov. de 2019. Disponível em: https://globoesporte.globo.com/mg/futebol/noticia/seguranca-do-mineirao-e-alvo-de-injuriaracial-de-torcedor-apos-cruzeiro-X-atletico-mg-olha-sua-cor.ghtml. Acesso em: 14 nov. 2019.

GOFFMAN, E. Ritual de Interação: ensaios do comportamento face a face. Petrópolis: Vozes, 2011.

GRANDE Dicionário Houaiss. Disponível em: https://houaiss.uol.com.br. Acesso em: 12 dez. 2019.

KERBRAT-ORECCHIONI, C. Os Atos de linguagem no discurso: teoria e funcionamento. Niterói: Editora da Universidade Federal Fluminense, 2005.

KERBRAT-ORECCHIONI, C. Abordagem intercultural da polidez linguística: problemas teóricos e estudo de caso. In: CABRAL, A. L. T.; SEARA, I. R.; GUARANHA, M. F. Descortesia e Cortesia: expressão de culturas. São Paulo: Cortez, 2017.

NETTO, A. V. S. et al. Código penal comentado. São Paulo: Saraiva, 2017.

SEARLE, J. R. Os actos de fala - um ensaio de filosofia a linguagem. Coimbra: Almedina, 1984. 